\title{
Natural Disturbances Regime as a Factor of Korean Pine-Broadleaved Forest Stand Shaping in the South of the Russian Far East
}

\author{
Olga N. Ukhvatkina*a,b, Alexander M. Omelko, \\ Alexander A. Zhmerenetsky ${ }^{\mathrm{b}}$ and Vladislav S. Guseva,b \\ ${ }^{a}$ Botanical Garden Institute FEB RAS \\ 142 Makovskogo Str., Vladivostok, 690024, Russia \\ ${ }^{b}$ Institute of Biology and Soil Science FEB RAS \\ 159100 let Vladivostoku Str., Vladivostok, 690022, Russia
}

Received 22.03.2015, received in revised form 19.07.2015, accepted 14.11.2015

Using dendroecological approach we reconstructed disturbance history of a mixed Korean pinebroadleaved stand in the south of the Russian Far East. Our results show that during the last two centuries there were no mass disturbances, which may lead to canopy destruction and change of the tree species composition. The main drivers of natural dynamics of the stand were small-and middlesize gaps, and they determine current tree species abundance in the stand. We revealed 20-years periodicity in occurrence of trees growth releases, connected with gaps formation. The stand was formed only under natural disturbances (without fires, loggings and catastrophic disturbances) during at least 1000-1200 years.

Keywords: dendroecology, Korean pine-broadleaved, forest communities, stand dynamics, disturbance history, age.

DOI: 10.17516/1997-1389-2015-8-4-441-458.

(C) Siberian Federal University. All rights reserved

* Corresponding author E-mail address: ukhvatkina@botsad.ru 


\title{
Режим естественных нарушений как фактор, определяющий формирование древостоя кедрово-широколиственного леса юга российского Дальнего Востока
}

\author{
О.Н. Ухваткина ${ }^{\mathrm{a}, \tilde{\sigma} *}$, А.М. Омелько ${ }^{\sigma}$, \\ А.А. Жмеренецкий ${ }^{\tilde{0}}$ В.С. Гусев ${ }^{\mathrm{a}, \boldsymbol{\sigma}}$ \\ ${ }^{a}$ Ботанический сад-институт ДВО РАН \\ Россия, 690024, Владивосток, ул. Маковского, 142 \\ ${ }^{\sigma}$ Биолого-почвенный институт ДВО РАН \\ Россия, 690022, Владивосток, пр. 100-летия Владивостока, 159
}

C использованием дендроэкологического подхода восстановлена история нарушений древостоя кедрово-иироколиственного леса, расположенного на юге российского Дальнего Востока. Установлено, что за время последних двух столетий не происходило массовых нарушений, которые повлекли бы за собой разрушение полога древостоя и смену его видового состава. Основой естественной динамики были окна небольшого и среднего размера, что определило текущее соотношение числа деревьев разных видов в древостое. Выявлена двадиатилетняя периодичность улучшения прироста деревьев, связанная с образованием окон. Длительность развития древостоя за счет естественных нарушений (без пожаров, рубок и катастрофических распадов) составляет не менее 1000-1200 лет.

Ключевые слова: дендроэкология, кедрово-широколиственные, лесные сообщества, динамика древостоя, режим естественных нарушений, возраст.

\section{Введение}

Описание динамических процессов в лесах, которые не были затронуты или значительно преобразованы хозяйственной деятельностью человека (девственных, малонарушенных, коренных), имеет огромное значение для формирования общих представлений о функционировании лесных экосистем, а также разработки мер по их сохранению и восстановлению. К числу таких лесов относятся сохранившиеся хвойно-широколиственные леса юга российского Дальнего Востока, представляющие собой остатки единой флоры, некогда существовавшей на значительных пространствах (Позднечетвертичные...,
2002). В настоящий момент территория материковой части юга российского Дальнего Востока - это единственное место, где сохранились малонарушенные лесные массивы и коренные древостои в пределах умеренной широтной зоны (Krestov, 2003).

Несмотря на значительное число работ, направленных на изучение кедровошироколиственных лесов (Соловьев, 1958; Моисеенко, 1963; Корякин, 2007 и др.), к настоящему времени большинство аспектов их структуры и динамики остаются малоизученными. Скудность доступной информации объясняется многими причинами. С одной стороны, сказываются особенности истори- 
ческого развития территории. Освоение юга российского Дальнего Востока русскими имеет историю всего около 150 лет (История Дальнего Востока..., 1989). Сведения о природных явлениях, происходивших до этого времени, и какие-либо доступные исторические хроники практически полностью отсутствуют, а давность метеонаблюдений в лучшем случае достигает 50-60 лет. С другой стороны, в кедрово-широколиственных лесах сосуществует относительно большое число древесных видов (до 30-40 на 1 га) с различными биологическими и экологическими характеристиками, и это приводит к возникновению трудно поддающихся типизации и классификации пространственновременных мозаик (Колесников, 1965). Также зачастую более 50 \% взрослых деревьев поражены сердцевинной гнилью, что не позволяет достаточно точно установить их возраст.

Одним из путей исследования динамических процессов в лесных сообществах является восстановление истории естественных нарушений древостоев с использованием дендроэкологических методик (Battles, Fahey, 1996; Fajardo, Gonzalez, 2009; Zielonka et al., 2010), которые позволяют проследить, какие события в древостое, имевшие место в течение нескольких прошедших столетий, повлияли на его формирование. Работы по исследованию кедрово-широколиственных лесов, основанные на дендрохронологической информации, единичны (Ловелиус и др., 2007; Таранков, 1973). Одним из первых исследователей, изучавших динамику лесов Дальнего Востока, был Б.А. Ивашкевич, предложивший «схему развития древостоев дальневосточных девственных кедровников» (Ивашкевич, 1929; Колесников, 1956). Первым опытом восстановления истории нарушений древостоя в дальневосточных хвойно-широколиственных лесах стала работа Ишикавы (Ishikava et al., 1999).

Использование дендроэкологических подходов в сочетании с дополнительной информацией о микрорельефе, следах пожаров в виде углей и подпалин, послерубочных пнях и т.д. (Восточноевропейские леса..., 2004; Смирнова и др., 2001; Смирнова, 2004) позволяет глубже заглянуть в историю древостоя и более точно выяснить, как происходило его развитие и что играло определяющую роль в его формировании. Это дает возможность прогнозировать пути развития древостоев, существующих в настоящее время, и использовать полученные знания для восстановления естественной структуры леса нарушенных участков. В этой связи цель работы: установить, какие нарушения происходили за последние столетия в древостое кедровошироколиственного леса и как они повлияли на его формирование. В частности, происходили ли интенсивные нарушения, которые могли бы привести к изменению его видового состава.

\section{Материалы и методы}

Район исследований

Исследование проведено на территории Верхнеуссурийского стационара Биологопочвенного института ДВО РАН. Стационар расположен на западном макросклоне южной части хребта Сихотэ-Алинь в бассейне $\mathrm{p}$. Правая Соколовка, притока второго порядка р. Уссури (4401’35,3”' с.ш., $134^{\circ} 12^{\prime} 59,8^{\prime \prime}$ в.д.).

Среднегодовая температура воздуха для данной территории составляет $0,9{ }^{\circ} \mathrm{C}$. Caмый холодный месяц - январь (абсолютный минимум минус $48^{\circ} \mathrm{C}$ ), наиболее теплый месяц - июль (абсолютный максимум $42{ }^{\circ} \mathrm{C}$ ). Среднегодовая величина осадков составляет 831,8 мм. Условия муссонной циркуляции, циклоническая деятельность и характер ре- 
льефа способствуют выпадению основного количества осадков в летне-осенний сезон. На зимний период (ноябрь-март) приходится только 20,8 \% осадков от их годового количества (Кожевникова, 2009). Ветровой режим связан с муссонным климатом, характерным для района исследований. В весенне-летний период преобладают ветра южных и юговосточных направлений, в осенне-зимний северных и северо-западных. Ветра слабые, их скорость обычно не превышает $3 \mathrm{~m} / \mathrm{c}$. В весенний и осенний период отмечаются дни, когда скорость ветра увеличивается, порывы достигают $20 \mathrm{~m} / \mathrm{c}$ и более.

Почвы в районе исследования бурые горно-лесные и горные буротаежные иллювиально-гумусовые. Для хвойношироколиственных пород наиболее характерны горно-лесные бурые почвы на делювиальных склоновых отложениях (Иванов, 1964).

Постоянная пробная площадь (ППП) № 71-2010 образована расширением постоянной пробной площади 1-1976 (Омелько, Ухваткина, 2012) с 0,64 до 1,5 га (150×100 м). Пробная площадь расположена в средней части склона западной экспозиции (уклон $22^{\circ}$ ), на высоте около 750 м над ур. м. Участок леса представляет собой позднесукцессионный древостой и относится к центральному типу кедровых лесов на верхней границе распространения кедра корейского, где он формирует смешанные формации кедрово-еловых и елово-широколиственных лесов (Колесников, 1956). Древостой образован деревьями следующих видов: Abies nephrolepis (Trautv.) Maxim., Acer mono (Maxim.), Acer tegmentosum (Maxim.), Acer ukurunduense Trautv. et Mey., Picea ajanensis (Lindl. et Gord.) Fisch. ex Carr., Pinus koraiensis Sieb. et Zucc, Taxus cuspidata (Siebold et Zucc. ex Endl.), Tilia amurensis Rupr., Betula costata (Trautv.) Regel., Sorbus amurensis
(Koehne), Cerasus maximowichzii (Rupr.) Kom., Ulmus laciniata (Trautv.) Mayr. В подлеске встречаются: Actinidia kolomikta Maxim. et Rupr., Schizandra chinensis (Turcz.) Baill., Ribes maximoviczianum Kom., Philadelphus tenuifolius Rupr. et Maxim. и Acer barbinerve Maxim.

\section{Сбор материала}

и предварительная обработка

Ревизии пробной площади проводили в 2009-2014 гг. Для задач данного исследования использованы результаты перечета и картирования древесных растений, всего 6479 шт. Относительное положение определяли с точностью до 0,1 м, учитывали все растения, начиная с имматурного возрастного состояния, учет ювенильных растений и всходов не проводился. Кроме того, на схеме пробной площади было отмечено расположение пней (73 шт.) с указанием вида дерева, где это было возможно.

Для дендрохронологического анализа были использованы керны, полученные с деревьев трех видов (P. ajanensis, P. koraiensis, A. nephrolepis), всего 405 шт. Предварительная подготовка кернов включала сушку, обрезку и повышение контрастности. Измерение ширины годичных колец проводили с использованием прибора Velmex ${ }^{\circledR}$ TA Measurement System с точностью до 0,01 мм. Кросс-датирование и проверку на пропущенные кольца выполняли с использованием программ Cofecha (Holmes, 1983) и TsapDos (Rinntech ${ }^{\circledR}$ ).

\section{Восстановление истории}

нарушений древостоя

Восстановление истории естественных нарушений выполнено с помощью методики «boundary-line release criterion» (Black, Abrams, 2003). Данная методика основана на предположении о том, что резкое уве- 
личение радиального прироста деревьев в древостое происходит вследствие улучшения условий, связанных с гибелью соседних деревьев (Lorimer, Frelich, 1989; Rubino, McCarthy, 2004), т.е. дерево реагирует увеличением прироста на улучшение условий. Для выявления таких моментов (так называемых growth release, сокращенно GR) для хронологии, полученной с каждого керна, вначале рассчитываются значения относительного изменения радиального прироста, выраженного в процентах (\%GC), по следующей формуле (Nowacki, Abrams, 1997):

$$
\% \mathrm{GC}=((\mathrm{M} 2-\mathrm{M} 1) / \mathrm{M} 1)^{*} 100
$$

где M1 - средний прирост за прошедшие 10 лет, включая текущий год (предварительный прирост); М2 - средний прирост за последующие 10 лет (последующий прирост). Усреднение по десятилетиям сглаживает изменения прироста, обусловленные ежегодными вариациями климата (Nowacki, Abrams, 1997).

Затем по данным, полученным на предыдущем этапе, строится график, где по оси абсцисс откладываются значения предварительного прироста (M1), а по оси ординат - относительное изменение прироста ( \%GC). Далее подбирается граничная функция (boundary line function, сокращенно BLF), описывающая изменение $\% \mathrm{GC}$ в зависимости от M1. Важным моментом является то, что при подборе BLF используются только 10 максимальных значений \% $\mathrm{GC}$, найденных в каждом классе предварительного роста, разбитого на интервалы 0,5 мм. Максимально возможные значения относительного изменения радиального прироста отрицательно связаны с предварительным ростом, т.е. дерево с небольшим приростом при улучшении условий увеличивает его в несколько раз, в то время как дерево с большим приростом не име- ет такой возможности (Black, Abrams, 2003). Преимущество функции BFL заключается в том, что ее использование позволяет выявить моменты улучшения условий роста при широком диапазоне значений предварительного прироста и исключает влияние изменений прироста, связанных со старением дерева, геометрией ствола и длинно-периодичными вариациями климата (Black et al., 2009).

Bce значения \%GC, которые превышают $20 \%$ от значения функции BLF при данной величине предварительного прироста (M1), свидетельствуют о резком улучшении условий роста дерева (GR). Поскольку каждое значение \% $\mathrm{GC}$ относится к определенному номеру дерева и дате, мы можем выяснить, какое из них показало улучшение условий.

Анализ частотной структуры распределения моментов увеличения прироста деревьев по годам выполнен методом прямого преобразования Фурье (спектральный анализ, ПО Statistica ${ }^{\circledR} 8.0$ ).

Для оценки степени нарушения древостоя пожарами и рубками проводилось обследование ППП 71-2010 на предмет наличия: а) обгорелых деревьев, пней, сухостоя, а также подпалин на живых деревьях (Сукцессионные процессы..., 1999; Drobyshev et al., 2004; Бобровский, 2010), б) вывальнопочвенных комплексов (ВПК) и других элементов микрорельефа (бугры, западины), в) валежа и пней разных стадий разложения, г) углей в почве, д) послерубочных пней (Смирнова, 2004; Ухваткина, Омелько, 2013). Также по возможности определялся возраст наиболее старых деревьев (подсчет колец на кернах) и свежего валежа (были взяты несколько спилов). Для определения наличия углей в почве в связи малой мощностью почв, характерной для горных районов, были обследованы ВПК различных деревьев. 


\section{Результаты}

Сумма площадей

поперечных сечений деревьев

и густота древостоя

На пробной площади всего отмечено 12 древесных видов (табл. 1), из которых 4 хвойных и 8 лиственных. По сумме площадей поперечных сечений живых деревьев на первом месте находится $T$. amurensis (23 \% от общей по древостою), следующие три вида $-A$. nephrolepis, $P$. ajanensis и P. koraiensis - имеют приблизительно равные доли (около $20 \%$ ). При этом густота деревьев A. nephrolepis составляет почти 550 шт/га, а у P. koraiensis она меньше в восемь с половиной раз, т.е. первый вид представлен многочисленными небольшими деревьями, в то время как у второго вида преобладают крупные деревья. Несколько меньшая доля (14 \%) приходится на B. costata, которая представлена в древостое главным образом малочисленными крупными деревьями. Площадь поперечных сечений деревьев оставшихся семи видов в сумме составляет меньше четырех процентов от общей, причем большая часть (2,6 \%) принадлежит A. ukurunduense. Деревья остальных шести видов встречаются единично и не играют на текущий момент существенной роли в сложении древостоя.

В сухостое преобладают деревья P. ajanensis и A. nephrolepis, вместе сумма их площадей поперечных сечений составляет около $80 \%$ от общей, причем соотношение числа стволов и площади поперечных сечений такое же, как и у живых деревьев. Единично встречены сухие деревья P. koraiensis, B. costata, T. amurensis и A. ukurunduense, сухостостой других видов не отмечен.

\section{История естественных нарушений древостоя}

В анализе было использовано 213 из 405 кернов, поскольку керны с числом колец менее 50 были исключены из анализа в связи с особенностями методики (Black, Abrams, 2003). Сердцевинная гниль присутствовала у 70 \% кернов P. koraiensis, $30 \%$ - P. ajanensis и

Таблица 1. Сумма площадей поперечных сечений (Ba) и густота деревьев (D) разных видов на постоянной пробной площади

\begin{tabular}{lcccccccc}
\hline \multirow{2}{*}{\multicolumn{1}{c}{ Вид }} & \multicolumn{2}{c}{ Ва, м $2 /$ га } & \multicolumn{2}{c}{ Ва, \% } & \multicolumn{2}{c}{$\mathrm{D}$, шт./га } & \multicolumn{2}{c}{$\mathrm{D}, \%$} \\
\cline { 2 - 9 } & живые & сухостой & живые & сухостой & живые & сухостой & живые & сухостой \\
\hline Tilia amurensis & 9,9 & 0,2 & 22,8 & 4,3 & 155,4 & 6,1 & 13,9 & 4,7 \\
Abies nephrolepis & 8,8 & 1,4 & 20,4 & 29,7 & 549,5 & 59,9 & 49,2 & 45,9 \\
Picea ajanensis & 8,4 & 2,4 & 19,5 & 52,1 & 182,6 & 52,3 & 16,4 & 40,1 \\
Pinus koraiensis & 8,4 & 0,4 & 19,4 & 8,2 & 65,2 & 8,3 & 5,8 & 6,4 \\
Betula costata & 6,1 & 0,2 & 14,0 & 4,4 & 37,1 & 2,3 & 3,3 & 1,7 \\
Acer ukurunduense & 1,1 & 0,1 & 2,6 & 1,2 & 115,2 & 1,5 & 10,3 & 1,2 \\
Ulmus laciniata & 0,2 & 0,0 & 0,5 & 0,0 & 3,0 & 0,0 & 0,3 & 0,0 \\
Taxus cuspidata & 0,2 & 0,0 & 0,4 & 0,0 & 1,5 & 0,0 & 0,1 & 0,0 \\
Acer mono & 0,1 & 0,0 & 0,2 & 0,0 & 1,5 & 0,0 & 0,1 & 0,0 \\
Acer tegmentosum & 0,1 & 0,0 & 0,1 & 0,0 & 4,5 & 0,0 & 0,4 & 0,0 \\
Sorbus amurensis & 0,0 & 0,0 & 0,0 & 0,0 & 1,5 & 0,0 & 0,1 & 0,0 \\
Cerasus maximowiczii & 0,0 & 0,0 & 0,0 & 0,0 & 1,0 & 0,0 & 0,0 & 0,0 \\
\hline
\end{tabular}


$25 \%$ - A. nephrolepis. Поскольку по этой причине возраст многих деревьев не может быть достоверно установлен, полученный материал был использован только для восстановления истории нарушений древостоя. Всего для дендрохронологического анализа было сделано 21108 измерений ширины годичных колец деревьев, из них 5829 шт. для P. koraiensis, 8667 шт. для $P$. ajanensis и 6612 шт. для A. nephrolepis. Хронологии охватывают временной промежуток 236 лет (1764-2000 гг.) для P. koraiensis, 248 лет (1752-2000 гг.) для P. ajanensis и 158 лет (1842-2000 гг.) для A. nephrolepis. Коэффициент корреляции между сериями составил у P. koraiensis 0,56 (чувствительность 0,21), у P. ajanensis 0,47 (чувствительность 0,22), у A. nephrolepis 0,47 (чувствительность 0,23).

Для каждого вида была подобрана граничная функция (BLF), описывающая максимальное изменение радиального прироста (\%GC) в зависимости от предварительного прироста (рис. 1a). Максимальная величина изменения прироста при предварительном приросте около 0,1 мм у P. koraiensis достигает $684 \%$, у P. ajanensis - $739 \%$, y A. nephrolepis 666 \%. При этом у P. ajanensis максимальный предварительный прирост составляет 6,5 мм, и возможность увеличения прироста сохраняется при предварительном приросте до 4 мм
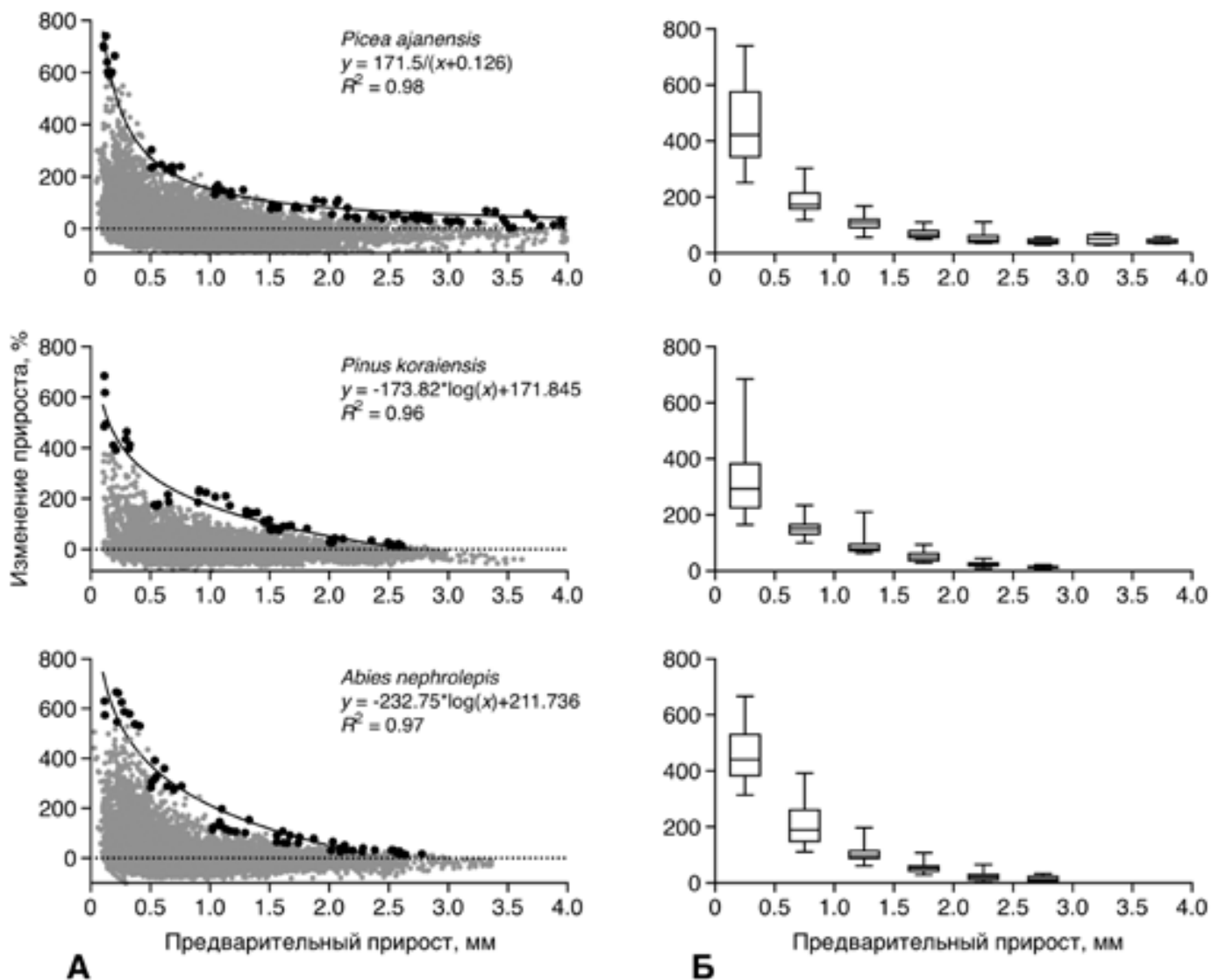

Рис. 1. Пограничные кривые (BLF) для Picea ajanensis, Pinus koraiensis и Abies neprolepis (А) и вариации (среднее, стандартное отклонение, минимум-максимум) максимального увеличения прироста по классам предварительного прироста 0,5 мм (Б) 
(кривая BLF асимптотически приближается к оси абсцисс). У деревьев P. koraiensis и A. nephrolepis максимальный предварительный прирост меньше практически в два раза и составляет 3,6 и 3,4 мм соответственно, а возможность увеличения прироста сохраняется до предварительных приростов 2,6 и 2,8 мм, при бо́льшем приросте возможно только его уменьшение. Кривые BLF показывают видовые различия изменения возможной реакции деревьев при разном предварительном приросте. Так, у P. ajanensis величина максимального увеличения прироста быстро снижается, и уже при предварительном приросте $0,5-1,0$ мм она составляет максимум $300 \%$ (увеличение в 4 раза), а при предварительном росте более 1,5 мм она не превышает $100 \%$ (рис. 1б). У деревьев A. nephrolepis максимальное увеличение прироста меньше, но скорость его снижения ниже (рис. 1б). В частности, деревья A. nephrolepis, имевшие предварительный прирост 0,5-1,0 мм, могут увеличивать прирост на 400 \% (в 5 раз). Кривая BLF для P. koraiensis сходна с таковой для A. nephrolepis, но выявляются более низкие значения увеличения прироста; при предварительном приросте 0,5-1,0 мм деревья P. koraiensis как и P. ajanensis могут увели- чить прирост не более чем в 3 раза (рис. 1б). При бо́льших значениях предварительного прироста разница в максимальном увеличении прироста между видами практически сглаживается.

Моменты резкого увеличения прироста деревьев (GR) были выявлены с использованием построенных BLF. На рис. 2 представлена диаграмма, иллюстрирующая распределение числа моментов увеличения прироста по декадам. При построении диаграммы все керны были объединены, поскольку только немногие из них содержали более 200 годичных колец. Общий период, в течение которого рассматривается история нарушений древостоя, составил 200 лет (с 1800 по 2000 г.). Нижняя граница этого периода была установлена по времени, когда в анализе начинали участвовать 10 и более кернов, верхняя граница заканчивается в 2000 г., поскольку последние 10 лет не могут быть учтены из-за усреднения, используемого в формуле (*).

Среднее по декадам резкое увеличение прироста составляет 23,7 \%, максимальные значения - 34,8 \% (1811-1820 гг.), 38,9 \% (19511960 гг.) и 35,3 \% (1991-2000 гг.), т.е. эти значения превышают среднее менее чем в два раза. Также более $30 \%$ деревьев показали

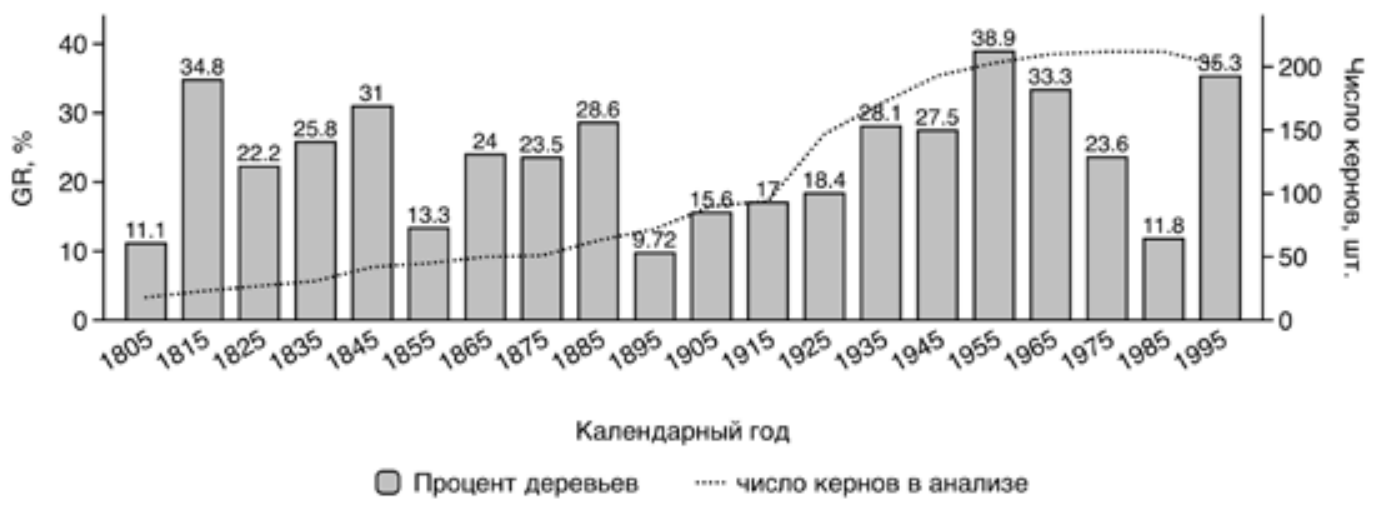

Рис. 2. Распределение моментов резкого увеличения прироста деревьев (GR) по декадам, выраженное в процентах от общего числа кернов, участвовавших в анализе в каждой декаде 
резкое увеличение прироста в декады 18411850, 1881-1890, 1961-1970 гг. Минимальное число деревьев (менее $15 \%$ ) отмечено в декады 1781-1790, 1801-1810, 1851-1860, 1891-1900, 1981-1990 гг.

Распределение числа моментов увеличения прироста по годам (рис. 3) показывает, что реакция деревьев разных видов разделена по времени. Так, в XX столетии несколько раз повторялась ситуация, когда вначале происходит массовое увеличение прироста деревьев $P$. ajanensis, а затем деревьев $P$. koraiensis и A. nephrolepis. На диаграммах это разделение наиболее отчетливо выявляется в периоды с 1934 по 1948 и с 1949 по 1970 г.

Анализ частотной структуры суммарного по всем видам распределения моментов резкого увеличения приростов по годам (рис. 3) показывает, что появление пиковых значений числа деревьев (GR) имеет периодичность, составляющую приблизительно 20 лет. При анализе распределений моментов улучшения роста по отдельным видам выделяются дополнительные периоды в 40 лет для P. koraiensis и 80 лет для P. ajanensis и A. nephrolepis.

Расположение на пробной площади деревьев, у которых выявлено резкое увеличение прироста в период с 1900 по 2000 г. по декадам, показано на рис. 4. До 1900 г. таких деревьев существенно меньше, что не позволяет делать заключение о характере их мозаик. В течение большинства декад деревья, показавшие резкое увеличение прироста, расположены на пробной площади практически однородно и не образуют группы. Исключение составляют декады 1941-1950 и 1961-1970 гг., в течение которых в центральной части пробной площади выявляются группы $A$. neprolepis.

Наличие следов пожаров и рубок

В процессе перечета древостоя на постоянной пробной площади не было обнаружено деревьев с подпалинами у основания, обгоревших пней, валежа и опавших ветвей. Также не было найдено пней послерубочного происхождения. Полученный дендрохронологический материал свидетельствует об отсутствии пожаров за период как минимум 248 лет (максимальная длина хронологии P. ajanensis), поскольку на кернах не были найдены пожарные отметины. Возраст отдельных экземпляров умерших деревьев P. koraiensis, определенный по спилам, достигает 600 лет (время отмирания составляет около 50-60 лет назад, определено

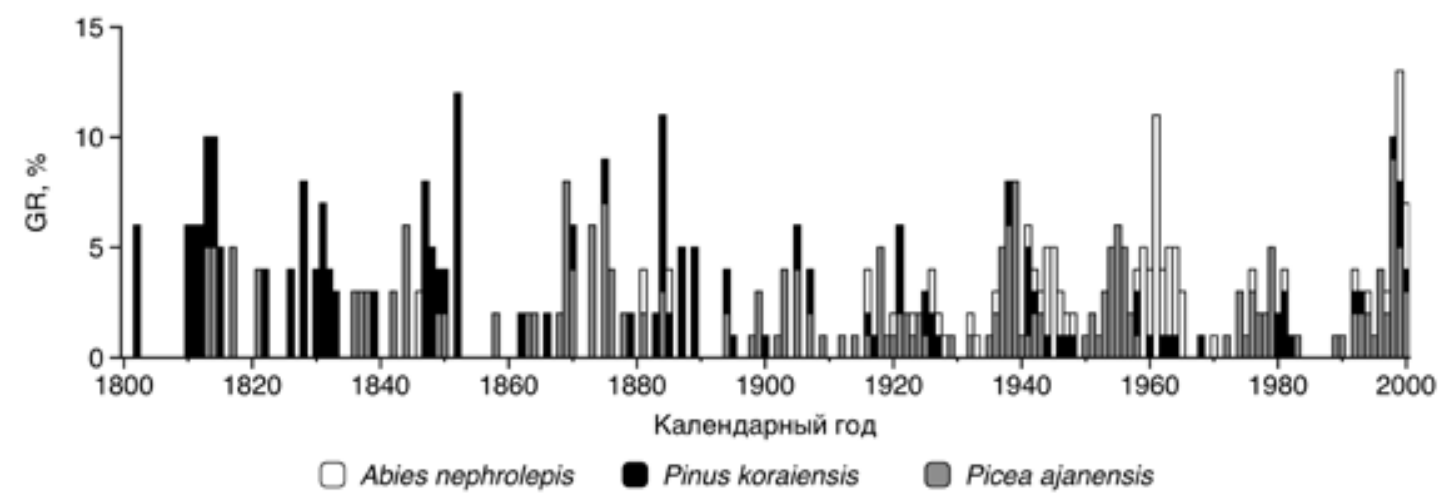

Рис. 3. Распределение моментов резкого увеличения прироста деревьев (GR) по годам, выраженное в процентах от общего числа кернов 

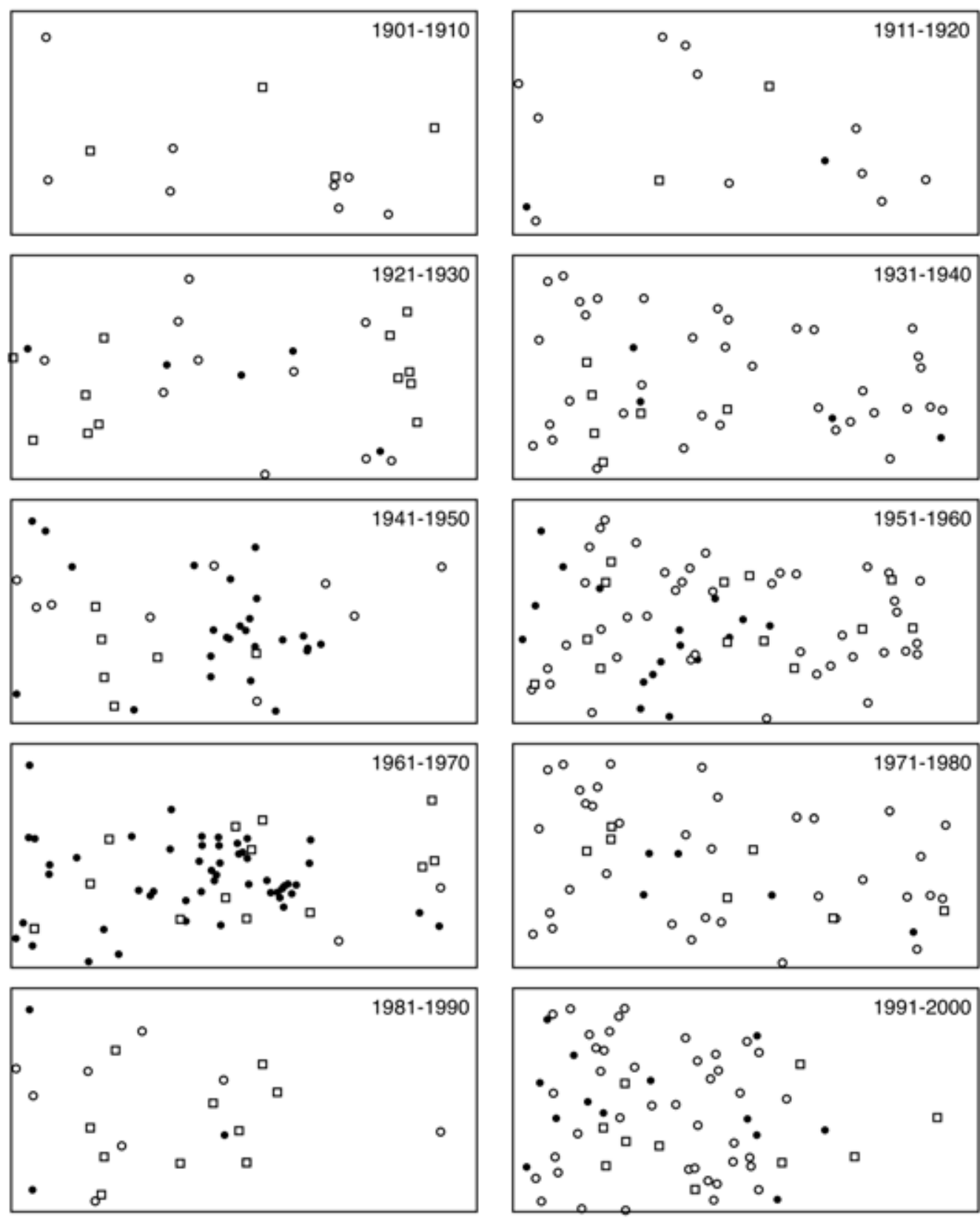

Рис. 4. Расположение на постоянной пробной площади деревьев с выявленными моментами резкого увеличения прироста по декадам в период с 1901 по 2000 г. Окружности - деревья Picea ajanensis, квадраты - Pinus koraiensis, точки - Abies nephrolepis

по возрасту появившихся в окне деревьев A. ukurunduense и A. tegmentosum). О том, что наблюдаемый древостой - это не первое послепожарное поколение, свидетельствует крупный валеж P. koraiensis, P. ajanensis и B. costata (его возраст не может быть опре- делен, но диаметр достигает 100 и более см), бугры и западины (диаметр более 3 м), оставшиеся после вывала крупных деревьев. В комах почвы на вывально-почвенных комплексах встречаются очень редкие угли размером до 0,3-0,6 мм. 


\section{Обсуждение}

Одной из первых задач при исследовании особенностей формирования древостоя было выявление в его истории сильных нарушений, к числу которых относятся рубки и пожары (Смирнова, и др., 2001). История лесопользования в районе исследования насчитывает не более 60-70 лет, по материалам лесоустройства в окрестностях Верхнеуссурийского стационара и части его территории первые промышленные рубки проводились с 60-х гг. прошлого столетия. Поэтому на любом участке, где были проведены хотя бы приисковые рубки, присутствуют послерубочные пни, которые за такое время полностью не разложились. На исследуемой пробной площади и в ее ближайших окрестностях таких пней обнаружено не было. Также обследование показало отсутствие различных следов пожаров. Присутствие бугров и западин, оставшихся после вывалов, пней и крупного валежа, в том числе P. koraiensis (остатки предыдущих поколений) на разных стадиях разложения, подтверждает отсутствие влияния пожаров (Восточноевропейские леса ..., 2004). Согласно предположению Ишикавы с соавторами (Ishikawa, et al., 1999), остается вероятность редкого прохождения древостоя беглыми низовыми пожарами, которые могли не оставить отметин на стволах и повредить только единичный подрост. Однако, по сообщениям Т.А. Комаровой (1992), занимавшейся вопросами, связанными с восстановлением кедрово-широколиственных лесов в исследуемом районе, даже беглый низовой пожар приводит к уничтожению подстилки, сухостоя и подроста, что обязательно повлияло бы на структуру мозаик прегенеративных растений (Омелько, Ухваткина, 2012). Таким образом, суммируя все полученные результаты, можно заключить, что с момента последнего прогорания сформировалось не менее двух поко- лений наиболее долгоживущего древесного вида-эдификатора (P. koraiensis), на что с учетом продолжительности его жизни (табл. 2.) потребовалось около 1000-1200 лет. Исходя из этого, влияние пожаров на естественную динамику исследуемого древостоя за последние столетия исключается.

Анализ распределения числа моментов улучшения роста деревьев за последние 200 лет показал, что в течение данного периода не происходило массовых разрушений древостоя. Число деревьев, изменение прироста которых свидетельствует о значительном улучшении условий при образовании окон, варьирует в небольших пределах, и максимальные значения (по декадам) превышают среднее менее чем в два раза. Несмотря на периодичность изменения их числа, резких скачков не наблюдается, т.е. одни прореагировавшие деревья постепенно сменяют другие.

Периоды, в течение которых отмечено максимальное число деревьев, показавших резкое увеличение прироста, совпадают с периодами частичных или массовых распадов пихтово-еловых лесов, выявленных на всей территории Сихотэ-Алиня Е.К. Козиным (2013). В этой же работе автор высказывает предположение о том, что такие распады, представляющие собой практически одновременное усыхание деревьев P. ajanensis, происходят и в древостоях смешанных лесов, но их трудно отследить из-за меньшего еe участия в сложении древостоя. Поэтому наиболее вероятно, что основную роль в процессах образования большого числа окон в исследуемом древостое играли отмирающие деревья $P$. ajanensis. Об этом, в частности, свидетельствует большое число полуразложившихся пней P. ajanensis возрастом около 50 лет, образовавшихся в декады 1951-1960, 1961-1970 гг., на которые приходится один из 
Таблица 2. Основные параметры, характеризующие древесные виды хвойно-широколиственных лесов

\begin{tabular}{|c|c|c|c|c|c|}
\hline Вид & $\mathrm{D}_{\max }$ & $\mathrm{H}_{\max }$ & $\mathrm{A}_{\max }$ & $\begin{array}{c}\text { Жизненная } \\
\text { стратегия }\end{array}$ & $\begin{array}{c}\text { Теневынос- } \\
\text { ливость }\end{array}$ \\
\hline Acer mono & $40-60$ & $18-22(25)$ & $250-300$ & $\mathrm{CS}$ & $\mathrm{OC}$ \\
\hline Acer tegmentosum & $20-30 *$ & $12-15(25)$ & $50-70 *$ & $\mathrm{R}$ & $\mathrm{T}$ \\
\hline Acer ukurunduense & $25-30$ & $5-7(12-14)$ & $60-80 *$ & RS & $\mathrm{T}$ \\
\hline Abies nephrolepis & $35-40(50)$ & $22-25(28)$ & $150-180(200)$ & RS & $\mathrm{T}$ \\
\hline Betula costata & $80-90(110)$ & $28-30$ & $200-250$ & $\mathrm{RC}$ & OT \\
\hline Cerasus maximowichzii & $20-30$ & $12-15$ & $70-100 *$ & $\mathrm{R}$ & $\mathrm{OC}$ \\
\hline Picea ajanensis & $100-110$ & $30-35(40)$ & $300-350$ & $\mathrm{SC}$ & $\mathrm{T}$ \\
\hline Pinus koraiensis & $120-150$ & $35-42$ & $350-400\left(600^{*}\right)$ & $\mathrm{C}$ & OT \\
\hline Taxus cuspidata & 100 & $15(20)$ & $700-800(1500)$ & $\mathrm{S}$ & $\mathrm{T}$ \\
\hline Tilia amurensis & $25-30$ & $80-100$ & $250-300$ & $\mathrm{RC}$ & OT \\
\hline Sorbus amurensis & $18-28 *$ & $15-20 *$ & $90-110$ & $\mathrm{R}$ & $\mathrm{OC}$ \\
\hline Ulmus laciniata & $50-60$ & $23-25$ & $200-230$ & $\mathrm{RC}$ & OT \\
\hline
\end{tabular}

Примечания: $\mathrm{D}_{\max }$ - максимальный диаметр, см, $\mathrm{H}_{\max }$ - максимальная высота, м, $\mathrm{A}_{\max }$ - максимальный возраст, лет (Усенко, 1968; Комарова, 1986); обозначение теневыносливости видов (Усенко, 1968): ОС - относительно светолюбивый вид, ОТ - относительно теневыносливый вид, Т - теневыносливый вид; типы жизненных стратегий (Grime, 1979): R - пионерные виды (ruderal), S - стресс-толерантные (stress-tolerant), C - конкурентные (competitive); * - собственные данные, превышающие найденные в литературе показатели.

пиков улучшения роста деревьев. Причинами массовой гибели деревьев и, как следствие, образования большого числа окон обычно называют ветровалы и повреждение древостоя насекомыми-вредителями (Bergeron et al., 2002; Zielonka et al., 2010 и др.). По нашим наблюдениям, на исследуемой территории ветровалы не играют основной роли в образовании окон, поскольку значительная часть деревьев усыхает на корню. Что касается повреждений насекомыми, то, по наблюдениям А.И. Куренцова (1941), насекомые предпочитают поселяться на мертвой древесине сухих и ослабленных деревьев, и это говорит о том, что подобные вспышки являются не причиной, а следствием нарушений. Связь усыхания древостоев с засушливыми периодами подтверждается во многих исследованиях (Aitken et al., 2008; Bijak, 2011; Pickes et al., 2012 и др.). В работе Е.К. Козина (2013) высказывается предположение, что периодичность появления засушливых годов связана с изменениями в солнечной активности, но эта гипотеза пока не получила подтверждения.

Вследствие постепенной и последовательной реакции деревьев на улучшение условий (у каждого вида она растягивается на десятилетие, и один вид следует за другим) ее двадцатилетняя периодичность не выявляется при разделении на декады. Различия в реакции разных видов могут объясняться несколькими причинами. По нашему мнению, основную роль в разделении реакции по времени играет не пространственное расположение окон в пологе, а различия в экологических особенностях видов. Деревья P. ajanensis способны реагировать на улучшение условий при предварительном приросте до 4 мм (рис. 1б), а при рассмотрении диаграммы реакции деревьев по годам (рис. 3) видно, что реакция деревьев $P$. ajanensis происходит раньше, чем у двух других видов. В то же время интенсивная реакция деревьев A. nephrolepis и P. koraiensis происходит позже (рис. 3). У P. koraiensis 
пределы такой реакции ниже (рис. 1б), чем у P. ajanensis и A. nephrolepis. Исходя из этого и в подтверждение предположений, высказанных ранее (Ухваткина и др., 2011; Омелько, Ухваткина, 2012), можно заключить, что деревьям $P$. ajanensis необходимо меньшее количество света для роста и развития, т.е. они способны медленно и долго расти под пологом и увеличивать прирост даже при небольшом осветлении. К такому же заключению пришел Ишикава с соавторами (Ishikava et al., 1999). Резкое увеличение прироста будет выявляться по данным, полученным с керна, но в то же время в абсолютном выражении оно довольно невелико. Деревья A. nephrolepis образуют одно поколение, сходное не абсолютным, но относительным возрастом (возрастным состоянием) (Ухваткина и др., 2011), которое расположено по всей пробной площади. За свою жизнь эти деревья показывают однократный пик массовой реакции (момент выхода в полог древостоя). Одна часть деревьев A. nephrolepis достигла полога в декаду 1941-1950 гг., другая - в 1958-1967 гг. Если говорить о деревьях P. koraiensis, то в предыдущих работах уже указывалась их способность к реакции на улучшение условий несколько раз за жизнь (Ухваткина и др., 2011). Размеры мозаики генеративных деревьев P. koraiensis существенно больше размеров исследуемой постоянной пробной площади, и поэтому расположение деревьев на пробной площади выглядит близким к однородному (Омелько, Ухваткина, 2012). В связи с этим, несмотря на отмечаемую периодичность в реакции деревьев P. koraiensis (20 лет), пиков массовой реакции выявить не удается, и деревья, для которых обнаружено резкое увеличение прироста, не располагаются группами по территории пробной площади. Кроме того, существуют различия в жизненных стратегиях всех трех видов (табл. 2). P. koraiensis отно- сится к конкурентным видам, которые отличаются максимальными размерами в древостое и наибольшей продолжительностью жизни. Для $P$. ajanensis свойственны черты как конкурентной, так и стресс-толерантной стратегии, т.е. способность длительное время выдерживать угнетение и продолжать рост. A. nephrolepis имеет черты пионерного (массовое заселение нарушенных территорий) и стресс-толерантного вида. Сочетание этих особенностей в совокупности с экологическими особенностями других видов (табл. 2), слагающих древостой, приводит к тому, что не происходит резких смен его видового состава. Выпавшие деревья заменяются непрерывно накапливающимся подростом (Омелько, Ухваткина, 2012), этот процесс протекает постепенно и не сопровождается частичными или полными распадами древостоя, описанными для пихтово-еловых лесов (Козин, 1981, 2013).

Анализируя мозаики деревьев, показавших резкое увеличение прироста за разные декады, мы не можем восстановить размеры и расположение окон, подобно тому, как это было сделано в работе Фравера с соавторами (Fraver et al., 2005). В этой работе авторы использовали моменты улучшения прироста как свидетельство о том, что после образования окна крона дерева оказалась полностью на свету. Исходя из чего предполагается, что освободившееся дерево находилось непосредственно в пределах окна и, объединив расположение нескольких смежных деревьев, ускоривших рост в одно время, можно приблизительно наметить контур окна. Такая методика восстановления размеров окон в пологе приведет к ошибкам при ее применении в условиях горных кедрово-широколиственных лесов. Древостой на исследуемой нами пробной площади расположен на склоне средней крутизны $\left(22^{\circ}\right)$, и основания стволов деревьев 
в верхней части пробной площади выше, чем вершины деревьев в нижней части пробной площади. Поэтому свет через образовавшееся окно может проникать глубоко под полог, приводя к увеличению прироста даже тех деревьев, которые фактически остаются под кронами более высоких деревьев и через некоторое время вновь оказываются в угнетенном состоянии. Тем не менее, исходя из полученных результатов, мы можем заключить, что за обследованный период окна в пологе образовывались практически равномерно по всей пробной площади (рис. 4). Это означает, что каждый отдельный пик реакции деревьев - это образование окон по всей пробной площади, а не в одной ее части. Размер окон был небольшим (когда выпадало одно дерево с кроной небольшой площади, например P. ajanensis) или средним (например, 2-3 смежных дерева P. ajanensis или одно дерево B. costata), в противном случае деревья, показавшие увеличение прироста, были бы расположены крупными группами. Единственное свидетельство о существовании крупного окна в виде большой группы деревьев A. nephrolepis (рис. 4) наблюдается в декаду 1960-1970 гг.

Преобладание окон таких размеров повлияло на процессы естественного возобновления и в конечном итоге на участие различных видов в древостое. В древесном ярусе в пределах пробной площади на основе анализа вертикального распределения высот древесных растений было выделено три подъяруса (Омелько, Ухваткина, 2012). Вследствие особенностей нарушений в первом подъярусе древостоя значительную долю в настоящее время занимают генеративные деревья P. koraiensis, но виргинильные растения, которым требуется значительное улучшение условий (второй подъярус), присутствуют только единично (Омелько, Ухваткина, 2012). Сформировался густой второй подъярус дре- востоя, практически полностью состоящий из виргинильных растений (находящихся в угнетенном состоянии) теневыносливых видов (табл. 2) - A. nephrolepis и P. ajanensis. При этом ряд более светолюбивых видов, требующих наличия крупных окон для успешного возобновления - A. mono, A. tegmentosum, C. maximowichzii и S. amurensis, - представлен единичными растениями. Во втором подъярусе отмечены угнетенные виргинильные растения этих видов (а также B. costata и многочисленные растения T. amurensis), которые не успели войти в полог древостоя до зарастания окна.

\section{Заключение}

Длительность развития исследуемого древостоя со времени последнего сильного нарушения составляет не менее двух поколений наиболее долгоживущего древесного вида-эдификатора (P. koraiensis), т.е. 10001200 лет. В течение этого времени древостой не подвергался влиянию таких нарушений, как пожары или вырубки. За обследованный с использованием дендроэкологического подхода двухсотлетний период не происходило массовых разрушений древостоя. Основную роль в процессах периодичного образования окон в древостое играли отмирающие деревья P. ajanensis. Замена погибших деревьев молодыми происходила непрерывно, на счет образования окон небольшого и среднего размера (вывал отдельных деревьев или групп по 2-3 дерева). Преобладание окон небольшого размера определило соотношение числа деревьев различных видов в древостое. Виргинильные растения P. koraiensis и ряд более светолюбивых видов присутствуют только единично, а густой второй подъярус древостоя практически полностью состоит из виргинильных растений теневыносливых видов. Разделение по времени реакции раз- 
ных видов определяется не пространственным расположением образовывающихся окон, а различиями экологических особенностей видов. Сочетание в древостое видов с различными жизненными стратегиями приводит к тому, что не происходит резких смен его видового состава. Выпавшие деревья заменяются непрерывно накапливающимся подростом, этот процесс протекает постепенно и не сопровождается частичными или полными распадами древостоя, описанными для пихтово-еловых лесов.

Работа выполнена при финансовой поддержке Российского фонда фундаментальных исследований, гранты № 13-04-01033, 14-04-32001, 14-04-10160.

\section{Список литературы}

Бобровский М.В. (2010) Лесные почвы Европейской России: биотические и антропогенные факторы формирования. М., Товарищество научных изданий КМК, 359 с. [Bobrovskii M.V. (2010) Forest soils of European Russia: biotic and anthropogenic factors of formation. Moscow, KMK Scientific Press, 359 p. (in Russian)]

Восточноевропейские леса: история в голочене и современность. (2004) М., Наука, 575 с. [Eastern European forests: history in the Holocene and the present. (2004) Moscow, Nauka, 575 p. (in Russian)]

Иванов Г.И. (1964) Почвы Приморского края. Владивосток, 107 с. [Ivanov G.I. (1964) Soils of the Primorsky (Krai) Territory. Vladivostok, 107 p. (in Russian)]

Ивашкевич Б.А. (1929) Девственный лес, особенности его строения и развития. Лесн. хозво и лесн. пром-сть, 10: 36-44; 11: 40-47; 12: 41-46 [Ivashkevich B.A (1929) A virgin forest, features of its structure and development. Forestry and forest industry [Lesnoe khoziaistvo i lesnaia promyshlennost'], 10: 36-44; 11: 40-47; 12: 41-46 (in Russian)]

История Дальнего Востока СССР с древнейших времен до XVII века. (1989) М., Наука, 375 c. [History of the Soviet Far East from ancient times till the 17th century. (1989) Moscow, Nauka, 375 p. (in Russian)]

Кожевникова Н.К. (2009) Динамика погодно-климатических характеристик и экологические функции малого лесного бассейна. Сибирский экологический журнал, 5: 693-703 [Kozhevnikova N.K. (2009) The dynamics of climatic characteristics and ecological functions of a small forest pond. Siberian Journal of Ecology [Sibirskii ekologicheskii zhurnal], 5: 693-703(in Russian)]

Козин Е.К. (1981) Схема развития древостоя девственного пихтово-елового леса. Лесное хозяйство, 10: 50-53 [Kozin E.K. (1981) Development scheme of a stand in a virgin fir-spruce forest. Forestry [Lesnoe khoziaistvo], 10: 50-53 (in Russian)]

Козин Е.К. (2013) Массовые распады темнохвойных лесов, как естественный этап возрастного развития. Бюллетень Ботанического сада-института ДВО РАН, 10: 4-14 [Kozin E.K. (2013) Mass decomposition of coniferous forests as a natural stage of age development. Bulletin of Botanical Garden-Institute FEB RAS, 10: 4-14 (in Russian)]

Колесников Б.П. (1956) Кедровые леса Дальнего Востока. Тр. ДВФ СО АН СССР. Сер. ботан., 2 (4): 262 c. [Kolesnikov B.P. (1956) Cedar forests of the Far East. Proceedings of the Far East Branch of the USSR Academy of Sciences, 2 (4): 262 p. (in Russian)]

$$
-455-
$$


Комарова Т.А. (1986) Семенное возобновление растений на свежих гарях (леса Южного Сихотэ-Алиня). Владивосток, ДВНЦ АН СССР, 224 с. [Komarova T.A. (1986) Seed regeneration of plants in fresh burned areas (forests of the South Sikhote-Alin). Vladivostok, Far Eastern Scientific Center of the USSR Academy of Sciences, 224. (in Russian)]

Комарова Т.А. (1992) Послепожарные сукщессии в лесах Южного Сихотэ-Алиня. Владивосток, ДВ0 РАН СССР, 224 с. [Komarova T.А. (1992) Post-fire successions in the forests of the South Sikhote-Alin. Vladivostok, Far East Branch of the USSR Academy of Sciences, 224 p. (in Russian)]

Корякин В.Н. (2007) Кедрово-цироколиственные леса Дальнего Востока России (динами$\kappa a$, состояние, пользование ресурсами, реабилитация). Хабаровск, 359 с. [Koriakin V.N. (2007) Cedar-broad-leaved forests of the Far East of Russia (dynamics, condition, use of resources, rehabilitation). Khabarovsk, 359 p. (in Russian)]

Куренцов А.И. (1941) Сем. Iрidaе на Российском Дальнем Востоке. М.-Л.: Изд-во Академии наук CCCP, 234 с. [Kurentsov A.I. (1941) Ipidae in the Russian Far East. Moscow, Leningrad, Publishing House of the USSR Academy of Sciences, 234 p. (in Russian)]

Моисеенко С.Н. (1963) Возобновление кедра корейского под пологом леса. Сб. тр. ДальНИИЛХ. Хабаровск, 5: 214-223 [Moiseenko S.N. (1963) Regeneration of Korean pines under a shelterwood. Collection of works of Far East Forestry Research Institute. Khabarovsk, 5: 214-223 (in Russian)]

Омелько А.M., Ухваткина О.Н. (2012) Особенности GAP-динамики в хвойношироколиственном лесу Южного Сихотэ-Алиня. Растительный мир Азиатской России, 1: 106113 [Omel'ko A.M., Ukhvatkina O.N. (2012) Features of GAP-dynamics in a coniferous- broad-leaved forest of the South Sikhote-Alin. The flora of Asian Russia, 1: 106-113 (in Russian)]

Позднечетвертичные растительность и климаты Сибири и Российского Дальнего Востока (палинологическая и радиоуглеродная база данных). (2002) Магадан, СВНЦ ДВО РАН, 369 c. [Late Quaternary vegetation and climates of Siberia and Russian Far East (palynological and radiocarbon database). (2002) Magadan, NESC FEB RAS, 369 p. (in Russian)]

Смирнова О.В. (2004) Методические подходы и методы оценки климаксового и сукцессионного состояния лесных экосистем (на примере восточноевропейский лесов). Лесоведение, 3 : 15-27 [Smirnova O.V. (2004) Methodological approaches and methods of assessment of climax and successional state of forest ecosystems (by the example of Eastern European forests). Forestry studies [Lesovedenie], 3: 15-27 (in Russian)]

Смирнова О.В., Бобровский М.В., Ханина Л.Г. (2001) Оценка и прогноз сукцессионных процессов в лесных ценозах на основе демографических методов. Бюллетень Московского общества испытателей природы, 106 (5): 25-33 [Smirnova O.V., Bobrovskii M.V., Khanina L.G. (2001) Assessment and prediction of successional processes in forest cenoses based on demographic methods. Bulletin of Moscow Society of Naturalists, 106 (5): 25-33 (in Russian)]

Соловьев К.П. (1958) Кедрово-широколиственные леса Дальнего Востока и хозяйство в них. Хабаровск, 367 с. [Solov'ev K.P. (1958) Cedar-broad-leaved forests of the Far East and the economy in them. Khabarovsk, 367 p. (in Russian)]

Сукиессионные процессы в заповедниках России и проблемы сохранения биологического разнообразия. (1999) СПб., РБО, 549 с. [Successional processes in national parks of Russia and 
problems of conservation of biological diversity (1999), St. Petersburg, Russian Botanic Society, 549 p. (in Russian)]

Таранков В.И. (1973) Введение в дендроклиматологию Дальнего Востока. Гидроклиматические исследования в лесах Советского Дальнего Востока. Владивосток, с. 7-23. [Tarankov V.I. (1973) Introduction to dendroclimatology of the Far East. Hydroclimatic studies in the forests of the Soviet Far East. Vladivostok, p. 7-23 (in Russian)]

Усенко Н.В. (1968) Деревья, кустарники и лианы Дальнего Востока. Хабаровск, 416 с. [Usenko N.V. (1968) Trees, shrubs and lianas of the Far East. Khabarovsk, 416 p. (in Russian)]

Ухваткина О.Н., Омелько А.М., Крестов П.В., Жмеренецкий А.А. (2011) Влияние частичных распадов древостоев кедрово-широколиственных лесов на процесс естественного возобновления. Журнал СФУ. Биология, 4 (4): 416-431 [Ukhvatkina O.N., Omel'ko A.M., Krestov P.V., Zhmerenetskii A.A. (2011) The effect of the partial decomposition of stands of cedarbroad-leaved forests on the process of natural regeneration. J. Sib. Fed. Univ., Biol., 4 (4): 416-431 (in Russian)]

Ухваткина О.Н., Омелько А.М. (2013) Оценка сукцессионного состояния древостоев хвойно-широколиственных лесов юга российского Дальнего Востока на основе популяционнодемографического подхода. Фундаментальные исследования, 11: 948-953 [Ukhvatkina O.N., Omel'ko A.M. (2013) Evaluation of the successional state of stands in coniferous- broad-leaved forests of the south of the Russian Far East on the basis of the population-demographic approach. Fundamental Research [Fundamental'nye issledovaniia], 11: 948-953 (in Russian)]

Aitken S.N., Yeaman S., Holliday J.A., Wang T., Curtis-McLane S. (2008) Adaptation, migration or extirpation: climate change outcomes for tree populations. Evolutionary Applications, 1: 95-111.

Battles J.J., Fahey T.J. (1996) Spruce decline as a disturbance event in the subalpine forests of the northeastern United States. Can. J. For. Res., 26: 408-421.

Bergeron Y., Denneler B., Charron D., Girardin M-Ph. (2002) Using dendrochronology to reconstruct disturbance and forest dynamics around Lake Duparquet, northwestern Quebec. Dendrochronologia, 20: 175-189.

Bijak Sz. (2011) Influence of drought on radial growth of Norway spruce in north-eastern Poland. TRACE - Tree Rings in Archeology, Climatology and Ecology, 9: 28-33.

Black B.A, Abrams M.D. (2003) Use of boundary-line growth patterns as a basis for dendroecological release criteria. Ecological Applications, 13: 1733-1749.

Black B.A., Abrams M.D., Rentch J.S., Gould P.J. (2009) Properties of boundary-line release criteria in North American tree species. Annals of Forest Science, 66 (2): 205.

Drobyshev I., Niklasson M., Angelstam P., Majewski P. (2004) Testing for anthropogenic influence on fire regime for a 600-year period in the Jaksha area, Komi Republic, East European Russia. Can. J. For. Res., 34 (10): 2327-2339.

Fraver S., White A.S. (2005) Identifying growth releases in den- drochronological studies of forest disturbance. Can. J. For. Res., 35: 1648-1656.

Grime J.P. (1979) Plant strategies and vegetational processes. New York, Wiley, 222 p.

Holmes R.L. (1983) Computer-assisted quality control in tree-ring dating and measurement. TreeRing Bull., 43: 69-78. 
Ishikawa Y., Krestov P.V., Namikawa K. (1999) Disturbance history and tree establishment in old-growth Pinus koraiensis-hardwood forests in the Russian Far East. Journal of Vegetation Science, 10: 439-448.

Fajardo A., Gonzalez M.E. (2009) Replacement patterns and species coexistence in an Andean Araucaria-Nothofagus forest. Journal of Vegetation Science, 20: 1176-1190.

Krestov P.V. (2003) Forest vegetation for Easternmost Russia (Russian Far East). Forest vegetation of Northeeast Asia. Kolbek J., Stutek M., Box E.E.O. (ed.) Dordrecht, Kluwer Academic Publishers, p. 93-180.

Lorimer C.G., Frelich L.E. (1989) A method for estimating canopy disturbance frequency and intensity in dense temperate forests. Canadian Journal of Forest Research, 19: 651-663.

Nowacki G.J, Abrams M.D. (1997) Radial-growth averaging criteria for reconstructing disturbance histories from presettlement-origin oaks. Ecological Monographs, 67: 225-249.

Pickles B.J., Egger K.N., Massicotte H.B., Green D.S. (2012) Ecomycorrhizas and climate change. Fungal Ecology, 5: 73-84.

Rubino D.L., McCarthy B.C. (2004) Comparative analysis of dendroecological methods used to assess disturbance events. Dendrochronologia, 21: 97-115.

Zielonka T., Holeksa J., Fleischer P., Kapusta P. (2010) A tree-ring reconstruction of wind disturbances in forest of the Slovakian Tatra Mountains, Western Carpithains. Journal of Vegetation Science, 21: 31-42. 